Journal of

Accident and Emergency

Medicine 1995

12, 149-150
Correspondence:

K.E. Jones,

Senior Registrar,

Accident and

Emergency

Department

Taunton and

Somerset Hospital,

Taunton,

Somerset TA1 5DA, UK.

\title{
Unusual presentation of tuberculosis to the accident and emergency department
}

\author{
K.E.JONES \& C.A.J.MCLAUCHLAN
}

Accident \& Emergency Department, Frenchay Hospital, Bristol

\section{SUMMARY}

A patient with localized, reactive tendinitis secondary to tuberculosis presented to the accident and emergency (A\&E) department. Tendinitis is a relatively common complaint, and it is important to consider uncommon systemic causes, including tuberculosis.

Key words: common, rare, systemic, tendinitis, tuberculosis

\section{CASE HISTORY}

A 34-year-old Indian male presented to the A\&E department complaining of bilaterally painful Achilles tendons, worse on the left. There was no recent overuse or trauma. He also complained of intermittent night sweats over the previous week. On examination there were bilateral tender, swollen Achilles tendons and paratendons. He was apyrexial. Treatment was commenced with Diclofenac, and the most painful leg placed in a below knee plaster for comfort.

On review 5 days later the painful tendinitis and night sweats were persisting. Swinging fevers were confirmed by home temperature recording. A tender cervical lymph node was found on further examination. An elevated C-reactive protein (57) and a plasma viscosity (1.85) were the only abnormal blood tests. A chest radiograph was normal.

A working diagnosis of atypical sero-negative arthritis (Reiter's Disease) was made, although he had no urethritis or iritis, and had tendinitis rather than arthritis. He was referred to the Department of Medicine as an out-patient, where this presumptive diagnosis was supported. A Mantoux test performed in the last 2 years was negative and he had received a BCG as a baby his native home of India. He had left India 12 months previously to work in the UK. Two weeks after the patient's initial presentation a rigor precipitated an emergency admission by his general practitioner under the care of the general physicians. Further investigation showed a $3 / 4$ positive Heaf Test, and an excision biopsy of the cervical node showed active tuberculosis. The patient made good general progress on triple therapy.

However, after starting therapy he developed further flitting tendinitis in his shoulder (requiring steroid injection), patella tendon, extensor pollicis longus, flexor carpi ulnaris and toe extensors.

\section{DISCUSSION}

Inflammation of the bursal sac (lying between the Achilles tendon and the calcaneum), or inflammation of the Achilles tendon itself, may be due to local or systemic causes. Local causes are usually secondary to trauma, such as ill-fitting shoes, or sporting overuse. ${ }^{1}$ Achilles tendinitis may occur as a reaction to systemic disease, e.g. rheumatoid arthritis seronegative arthritis, ankylosing spondylitis, gout, gonorrhoea and tuberculosis. ${ }^{13}$

The following should raise the index of suspicion for a systemic cause: bilateral tendinitis, ${ }^{4}$ a slow onset of symptoms and persistent severe symptoms not relieved by local measures. In young males particularly, symptoms in this area are often an early manifestation of ankylosing spondylits. ${ }^{1}$ Inflammation of the Achilles tendon tends to be more proximal in systemic disease than in traumatic causes. $^{3}$

Tuberculosis may cause Achilles tendinitis in two ways. Tubercle bacillus may invade the tendon sheath directly, causing progressive local symptoms and signs. ${ }^{5}$ Diagnosis is difficult, ${ }^{3}$ and excision of the lesion is required.

Secondly, Achilles tendinitis may occur rarely as an early localized reactive phenomenon of tuberculosis, progressing to a widespread flitting tendinitis. The literature reports several cases of localized infection, ${ }^{5}$ but no cases of a reactive tendinitis have been reported since 1960 .

It is important to consider the wide range of systemic diseases as a possible cause of tendinitis, 
K.E. Jones \& C.A.J. which is a common complaint presenting to the A\&E McLauchlan

department. Furthermore, tuberculosis must be considered when unusual soft-tissue problems present in patients who are from the Asian subcontinent.

\section{ACKNOWLEDGEMENTS}

Grateful thanks to Mrs J. Beddoe for preparing the manuscript, and Dr R.J. White and Dr V. Kyle for their advice.

\section{REFERENCES}

1. Crenshaw A.H. (1992) Campbell's Operative Orthopaedics, Eighth Edn, p. 1945. Mosby Year Book, Missouri.
2. Goldberg I. \& Avidor I. (1985) Isolated tenosynovitis of the achilles tendon. Clinical Orthopaedics and Related Research 194, 185-188.

3. Golding D.N. (1979) Common Rheumatic Disorders, p. 88. J. Wright \& Sons Ltd, Bristol.

4. Kelly P.J., Karlson A.G., Weed L.A. \& Lipscomb P.R. (1967) Infection of synovial tissues by mycobacteria other than mycobacterium tuberculosis. Journal of Bone and Joint Surgery (Am) 49, 1521-1530.

5. Mosikowitz R.W. (1975) Clinical Rheumatology - A Problem Orientated Approach, pp. 203, 258. Lea \& Tebiger, Philadelphia.

6. Pfeiffer K.M. (1988) Handchirurgie, Mikrochirurgie, Plastische, Chirurgie 20(4), 218-219.

7. Yale I. (1980) Podriatric Medicine Second Edn, pp. 267-268. Williams and Wilkins, Baltimore/London. 